\title{
Research on the Teaching Principles of English Reading on the Micro-learning Platform
}

\author{
Yongying Zhou ${ }^{1, *}$ \\ ${ }^{1}$ Xingzhi College of Xi'an University of Finance and Economics, Xi'an, Shaanxi 710038, China \\ *Corresponding author. Email: samuelzhou@qq.com
}

\begin{abstract}
This paper studies the teaching principle of English reading course on the micro-learning platform. It focuses on discussing the characteristics and principles of the teaching design of English reading on the micro-learning platform. Micro-learning has some characteristics like flexibility and interactivity. The teaching practice has been carried out based on micro-learning platform. After the practice, the author summarizes some teaching principles in English reading teaching. To optimize the effect of reading teaching, teachers should give full play to the advantages of micro-learning platform such as high efficiency and interest-led guidance. On the micro-learning platform the English reading teaching process should follow the principles of autonomy, integrity interest and cooperation.
\end{abstract}

Keywords: Micro-learning; English Reading; Teaching Principles

\section{INTRODUCTION}

Nowadays, the cultivation of comprehensive language ability is the common goal of English education, and English reading ability is one of its important objectives. Under the traditional conceptual model, English reading is for students to master the knowledge points of words, sentences, paragraphs and articles in reading articles under the guidance of teachers, and understand the details and general idea of the articles. Students are still in passive position in teaching. At present, as a popular mode, micro-learning takes great advantage of network information. With the popularity of mobile internet devices, micro-learning has become an important way for Chinese learners to obtain knowledge and information, especially it is deeply welcomed by the new generation of learners. There are many forms of micro-learning, such as MOOCS, short video teaching etc., which allow learners to learn independently at any time and at any place, either in class or after class. We can say that Micro-learning can occur in most scenes of life. As long as there are electronic devices connected to the network and appropriate learning resources, the conditions of Micro-learning will be established. In addition to this new learning method, which makes learning no longer limited by time and space, the characteristics of micro-learning are also reflected in its "micro" character. The "micro" here can not only indicate that the learning content is short and exquisite, but also reduce the grand knowledge to a condensed content. Micro-learning does not have to stick to the narrow teaching design ideas. Teachers can select the essence of the teaching content, control the teaching time, and make the teaching both in depth and breadth. The concept of micro learning is innovative, with extensive resources and diverse forms. English reading teaching should also update teaching ideas and methods to face up to the new generation.

At present, WeChat, Weibo, QQ and other internet social media no longer only serve for interpersonal communication only. Meanwhile, they are also the main ways to obtain information and broaden our horizons, and every day they integrate worldwide information for the public. As the trendsetters, learners maintain strong interest in educational activities based on these public platforms. Some scholars survey the learning behaviors of mobile media and the study shows that $100 \%$ of college students use WeChat and QQ. And $95 \%$ of college students like the official account of learning class. $32.4 \%$ of them read the official accounts. Therefore, it shows that the vast majority of college students are willing to acquire knowledge from internet learning platforms. In addition, the survey on the purpose of using WeChat finds that more than $68 \%$ of the learners studied relevant knowledge with the help of WeChat public account. As a result, it can be confirmed that college students' learning has been inextricably linked with internet social media, which has laid a good foundation for independent learning on micro-learning platform.

\section{THE CHARACTERISTICS OF MICRO-LEARNING}

In the new era of education, the rapid development of modern information technology has driven the application and promotion of micro-learning mode, and the research on micro-learning in the educational field is also increasing. In the specific implementation process, teachers need to combine the actual needs of learners and use modern teaching equipment to push learning content for students in the form of micro-learning, while learners 
need to independently choose learning time, place and contents according to their own real situation, and use network technology and internet terminals to obtain corresponding learning resources. At the same time, teachers and learners can keep in touch with each other by communicating and discussing with each other in case of problems and difficulties, to mobilize learners' enthusiasm and initiative, and further broaden learners' horizon and strengthen learners' ability without increasing their extra burdens.

Micro-learning can be applied no matter when and where the teaching and learning take place, and the learners' background knowledge and ability vary greatly. Micro-learning uses its advantages to meet different teaching requirements in complex and changeable scenarios. Therefore, its most prominent feature is flexibility and interactivity.

\subsection{Flexibility}

First, the learning approach of micro-learning is flexible. Due to the advantages of modern network technology, micro-learning will not be limited by the traditional classroom, teaching materials and teaching environment. Learners also get rid of the constraints of time and space using the web browser or smartphone application software to carry out learning. Second, the micro-learning mode is flexible. Micro-learning can decompose the learning task points according to Bloom's classification theory of educational goals. It can also modularize knowledge points. Micro-earning essentially realizes the personalization and diversification of the learning process. Third, the learning resources of micro-learning are flexible. Micro-learning not only meets the purposeful learning needs, but also uses fragmented time to learn on electronic devices. Learners can systematically and comprehensively learn a complete knowledge system, check and make up deficiencies and learn a certain knowledge point, and choose learning content according to their own condition and will

\subsection{Interactivity}

The micro-learning scenario uses the advantages of network interconnection to bring a new concept to interactive learning. Wen Qiufang believes that concept in English teaching is based on the understanding of interaction, and its strategy is the regulation and control of interaction. Micro-learning is learner-centered. In that case teaching design plays a guiding role. Interactive teaching is the interaction between teachers and students, between students and students in network environment, and even with artificial intelligence. Learners are in an active position in interaction. Micro-learning can stimulate learners' learning motivation, improve learning autonomy and effectiveness, and enable learners to improve language output ability in interaction.

\section{TEACHING PRINCIPLES OF ENGLISH READING COURSE}

In essence, the goal of English reading teaching is to cultivate and improve the input and output of English ability. According to Bloom's classification theory of educational objectives, the primary goal of English reading teaching is to master the basic knowledge of English reading, which refers to mastering the meanings of vocabulary, sentences, paragraphs, text structures and so on. Then learners are taught to use certain reading skills, such as skimming and skipping, so as to locate important keywords and grasp the overall structure of the article through the keywords and cohesive words in the article. Thus learners' cross-cultural ability will be improved. The language input ability of English reading should eventually be transformed into language output ability. Language is the carrier of culture. While acquiring English knowledge, learners will subconsciously understand the Chinese and western cultural elements carried by the content, meet the requirements of cross-cultural communication and creatively use language skills.

\subsection{The Principle of Autonomy}

In traditional English teaching, the whole reading process is led and driven by teachers. Reading teaching focuses on some shallow knowledge, such as interpreting the meaning and usage of vocabulary and sentences, so as to help learners understand the literal meaning of paragraphs and articles. The whole process is relatively difficult to improve learners' autonomous learning ability.

In English reading teaching, how to make learners voluntarily and enthusiastically devote themselves to learning is the first thing to face. The flexibility of learning time, place and content on the micro-learning platform provides a certain guarantee for learners' autonomous learning. When preparing for English reading course, teachers have to face learners' personalized behavior. English reading teaching is a process in which teachers guide learners to have a relationship with the text. In English reading teaching, learners are reconstructing knowledge. The teaching of English reading in micro-learning should take learners as the center and subject, and learners should be able to complete the whole learning process independently. No matter what kind of micro-learning platform has been used, curriculum design should follow the principle of learner autonomy. Therefore, the design of English reading course should be in line with learners' actual ability and experience. According to the cognitive theory put forward by Bloom, learners' reading and recitation not only belong to the memory process of knowledge but also belong to the surface cognitive level, while the understanding of the overall paragraph or text context of the reading text and the grasp of the central ideology are the deep cognitive level. English reading teaching should ensure that learners participate in multi-sensory learning activities. Eyes and ears are 
responsible for the input of information, and the linkage of hand, mouth and brain is responsible for the output of information. Only under the coordination of brain can all senses improve their reading skills. Therefore, sound, picture and text should be combined to integrate learners' senses into reading materials.

On the micro-learning platform, learners' autonomy is also reflected in their speculative understanding of reading materials. English reading teaching should not stay on the language itself, and learners can't extricate themselves only on words and sentences. The teaching on the micro-learning platform should break this dilemma. The designers of English reading teaching should emphasize critical thinking. Indeed, internet provides the basic material of micro-learning. In the era of internet, information explosion brings complex information experience to contemporary young learners. This unprecedented situation brings not only opportunities, but also some negative problems, that is, the proliferation of fragmented information, spam and false information. Because learners born in the new millennium are in the age of internet, the negative characteristics of these information lead many of them to only accept the superficial side of the information but lack deep insight into the information. Micro-learning platform teaching should first avoid the fragmentation of teaching content, set up teaching links to guide learners to think deeply about reading materials, and transform passive reception of information into active thinking. In this way, learners can establish their own knowledge system and thinking structure, and establish correct values.

\subsection{The Principle of Integrity}

The starting point and foothold of English reading teaching is the application of language knowledge. However, the single text teaching of traditional English reading teaching is easy to cause learners' superficial and superficial understanding of text reading. From the perspective of micro learning, English reading teaching should integrate the content and structure of teaching materials and systematize the process of memory understanding application analysis evaluation creation proposed by bloom. For example, when learners read a professional article on introducing the development of new energy vehicles, they can import relevant vocabulary expression and background knowledge through pre-reading or background introduction in the teaching design, and also let students think about the problems brought by traditional energy vehicles. This will help learners compare traditional energy vehicles with new energy vehicles and gradually understand and absorb the learning contents.

The integrity of instructional design is also reflected in the transfer of language ability from knowledge input to ability output. Overall language teaching requires that listening, speaking, reading and writing abilities should be cultivated at the same time. Especially in English reading teaching, we should highlight reading and writing as a whole and pay attention to the linkage of their relationship. In English teaching, reading is an important means to improve writing level. When reading, the expansion of vocabulary, the cultivation of language sense and the analysis of grammatical structure play a fundamental role in the development of English writing ability.

In the teaching design, we should also grasp the integrity of the reading process. Teachers can give full play to the advantages of micro learning platform and use audio-visual paintings to introduce themes, so that learners can have cognition and thinking about the relevant contents of the theme. After mastering the basic general idea of the reading article, the teacher guides them to understand the central idea of the article by thinking about the viewpoint of the contents.

\subsection{The Principle of Interest}

Interesting teaching contents and activities can attract learners' intention and guide learners to achieve higher educational goals. At the same time, interest is also one of the driving forces in the teaching process. In teaching design, the setting of scenarios can activate learners' enthusiasm for participation. Problem-solving orientation can enable students to find the solutions. Before the preparation of the course, we should investigate and learners' interest, and further stimulate their inquiry ability by exploring the problems of learners' interest, which firmly grasps the learners' attention and makes them devote themselves to internalizing of knowledge on the micro-learning platform.

\subsection{The Principle of Cooperation}

Cooperative learning refers to the interaction and communication between learners in group based on their autonomous learning. In order to pursue good learning effect through cooperation, learners takes the group achievement as the assessment standard. Micro-learning platform also advocates the form of thematic task-based learning to increase the interaction and cooperation between teachers and learners. Under the principle of cooperation, teachers are no longer the absolute authority and dominant position, but make learners' assistants in order to consolidate and review knowledge.

Under the concept of cooperative learning, the auxiliary learning platform for extracurricular learning based on WeChat is developed to promote students to practice experiential cooperative ability in the form of contests, English salons and lectures. For example, when teachers prepare a reading class on the topic of how to avoid injury in natural disasters, there are many words involved in natural disasters such as earthquake, volcanic eruption, tsunami and flood. Teachers can make learners to discuss keywords in groups with the help of micro-learning platform 


\section{CONCLUSION}

As a currently popular teaching mode, micro-learning is inherently flexible and interactive compared with traditional class. In English reading teaching, the micro-semester is boldly used to stimulate learners' interest and promote the cultivation of learners' cooperative learning ability. In the teaching design, the learner is guided to acquire the knowledge from the superficial understanding to the application and even innovation.

\section{REFERENCES}

[1] Huang Ying. Analysis of Strategies for Cultivating Literary Thinking in College English Reading Teaching [J]. Modern Vocational Education, 2021(32): 164-165

[2] Jun Wu. Exploration and Practice of Micro-learning in Teaching. Computer Age. Vol. 30(2013) No.7, pp. $55-56$.
[3] Wang Han. Research on the Application of Interactive Teaching Method Based[D]. Harbin Normal University, 2021.

[4] Wang Hansong. Comment on Bloom's Theory of Educational Classification in Cognitive Field [J]. Journal of Nanjing Normal University (SOCIAL SCIENCE EDITION), 2000, (03): 65-71

[5] Yang Huajuan. Research on the Integrated Teaching of English Reading [J]. Teaching monthly middle school edition (Teaching Reference), 2020, (z2): 55-57

[6] Zhang Yuxing. Research and Implementation of Micro-learning Platform Under New Media Environment [D]. Liaoning University, 2020.

[7] Zhenhong Zhang, Qingying Yang, Zhi Han. A Study on Micro-learning: Current Situation and Future. China Educational Technology. Vol. 33 (2013) No.11, pp. 13-20. 